\title{
LA PRODUCCIÓN LITERARIA EN EL IMAGINARIO RELIGIOSO CUBANO
}

\section{THE LITERARY PRODUCTION IN THE CUBAN RELIGIOUS IMAGINARY}

Juan Manuel Saldívar Arellano*

RESUMEN

La producción literaria cubana, antillana o afronegrista, ha marcado además de una época "real maravillosa", una perspectiva de análisis relevante para entender las singularidades culturales del pasado que se gestan en el presente entre las diversas manifestaciones religiosas cubanas. El objetivo de este artículo es analizar cómo las ideas religiosas de ancestro africano han construido múltiples identidades culturales en los imaginarios del Gran Caribe y las Antillas. En lo que refiere al caso cubano, se puede aseverar en la identificación del "negro" como parte de una extensa discusión que conduce a entender las situaciones culturales en sentidos amplios de significado. Finalmente, matizar las horizontalidades simbólicas desde la literatura es relevante en sentido de extender, no solo la discusión sobre la temática, sino futuros planteamientos entre lo imaginativo, lo representativo y lo existente.

PALABRAS CLAVE: CUBA * LITERATURA * IDENTIDAD CULTURAL * RELIGIÓN * NEGROS

\section{ABSTRACT}

The cuban literary production (antillana o afronegrista), it was land mark, beside a real wonderfull time in live also a relevant analysis that helped to understood the singularity of the cuban religious manifestation. How that is the African ancestors have developed multiple cultural identities from the mystical Gran Caribe and the Antillas. In regards to the Cuban case, we can confirm the identification of a black person a part of an extensive discussion that leads to understand the cultural situation in a vast sense of the meaning. Finally, the horizontal symbolic mixed; of the point view of literature it's relevant in the sense to extended, not only the theme of the discussion, even though future statement between the imaginative, the representative and the real existent.

KEYWORDS: CUBA * LITERATURE * CULTURAL IDENTITY * RELIGION * BLACKS

\footnotetext{
* Universidad de Tarapacá, Chile.
} jsaldivar@pucp.pe 


\section{INTRODUCCIÓN}

Menegildo [...] Se hallaba, por vez primera, ante las cosas grandes, de las cuales el altar de Salomé solo resultaba un debilísimo reflejo, sin fuerza y sin prestigio verdadero. A la altura de sus ojos, una mesa cubierta de encajes toscos sostenía un verdadero cónclave de divinidades $y$ atributos [...] En el centro, sobre la piel de un chato tambor ritual, se alzaba Obatalá, el crucificado, preso en una red de collares entretejidos. A sus pies, Yemayá, diminuta Virgen de Regla, estaba encarcelada en una botella de cristal. Shangó, bajo los rasgos de Santa Bárbara, segundo elemento de la trinidad de orishas mayores[...] - ¡Entonse vamo a empezal por la limpieza! —-sentenció el brujo. Untando sus dedos en la manteca de corojo que contenía una pequeña vasija de porcelana, el viejo Beruá engrasó la frente, las mejillas, la boca y la nuca de Menegildo.A cada tres pasos sedetenía para arrojar un puñado de maíz tostado, bañado en vino dulce, sobre las espaldas temblorosas del paciente. - ¡Sará-yé-yé! ¡Sará-yé-yé! [...] Después de esta invocación, el brujo se plantó ante Menegildo: - ¡Sará-yé-yé! ¡Sará-yé-yé! iSará-yéyé! Calló el tambor. Callaron las voces (Carpentier, 1986: 34-35).

Este artículo pretende mostrar parte de un estudio etnográfico más amplio en el cual se discuten cuestiones relacionadas a las tradiciones religiosas de origen cubano, sobre todo enfocado en la Santería como religión de ancestro africano. De esta manera, se pretende exponer un panorama somero en torno a la producción literaria y la construcción de identidades religiosas en Cuba. Por tanto, el artículo no se centra en una crítica literaria particular, sino en señalar algunos trabajos relevantes para construir una plataforma discursiva en torno a la identidad cultural cubana ligada a las religiosidades populares. En este sentido, es relevante señalar cómo los procesos de esclavitud africanos en América sostuvieron, además de manumisiones ideológicas, diversos panoramas de recreación imaginaria, tentativos para reflexionar sobre las manifestaciones culturales contemporáneas. Las tradiciones religiosas entre grupos de esclavos africanos en el continente, fueron adoptadas en diversos espacios del Caribe, siendo la isla de Cuba una de las más extensas en sus expresiones culturales. Fernando Ortiz (1940), sostenía que el avance de la isla no solo se había encontrado en el azúcar y el tabaco, sino también en el desarrollo cultural como la música, el arte, la poesía, la literatura y otros remanentes que situaron los procesos identitarios como parte de una amalgama en la cual identificaba al "negro" como nuevo integrante de las Américas. Por ejemplo, la literatura cubana permitió observar otras maneras culturales expresadas como imaginarias en el territorio de los orichas que llegaron de África. Lydia Cabrera en sus aportes etnográficos, manifestó una serie de atributos literarios en sus aproximaciones a las tradiciones de procedencia africana en Cuba. Algunas de sus obras como El monte (1954), Anagó, vocabulario Lucumí (1957),Otániyebiyé, las piedras preciosas (1970), Yemayá y Ochún (1974), Koekoiyawó, aprende novicia: pequeño tratado de regla Lucumí (1980), hace explícito la noción de tradición cultural a través de la expresión como extensión imaginaria y territorializada en suelo cubano.

El artículo se encuentra dividido en cinco apartados, el primero de ellos considera los aspectos metodológicos de la investigación etnográfica sobre la Santería cubana desarrollada como parte de la tesis doctoral elaborada entre los años 2009-2014 en las ciudades de La Habana, Cuba; Lima, Perú; La Paz, Bolivia y Santiago, Chile. El segundo manifiesta algunos antecedentes históricos sobre los procesos de esclavitud durante la Colonia en Cuba. El tercero pretende describir algunas de las tradiciones religiones más representativas en suelo cubano, como son: la Santería, el Palo Monte y el espiritismo. El cuarto apartado sitúa algunos antecedentes sobre la negritud desde una posición de reivindicación de las culturas negras a través de la literatura conocida como negrista o afro-antillana en el Caribe y Cuba. El quinto apartado muestra la conclusión del trabajo, destacando 
cómo los estudios literarios afro-cubanos no se encuentran tan distantes de la Antropología, pues más allá de las narraciones etnográficas visibles en ambos contextos retóricos, la producción literaria ha sido una plataforma que mantiene información detallada sobre sucesos históricos, simbólicos y culturales de las tradiciones religiosas en el imaginario cubano.

\section{ESTRATEGIA METODOLÓGICA}

Este artículo es parte de un estudio etnográfico más amplio desarrollado entre los años 2009-2014, en las ciudades de La Habana, Lima, La Paz y Santiago. El objetivo fue situar la transnacionalización de la Santería cubana como religión que cruza fronteras políticas, económicas y culturales, manifestando alternativas religiosas en los lugares donde se establece a partir de las prácticas activas entre emigrados cubanos y participantes locales. El presente trabajo muestra parte del marco histórico sobre la reivindicación de las culturas negras en Cuba como antecedente provocado por los procesos coloniales en América. Además, procura manifestar cómo la producción literaria afronegrista fue una plataforma que resaltó las tradiciones religiosas de ancestro africano en la isla, sosteniendo la idea del negro como factor determinante en la multiplicidad de las identidades culturales cubanas. Se utilizaron una serie de estrategias metodológicas, sobre todo aquellas que lograran localizar a los practicantes de Santería, tanto cubanos como peruanos, bolivianos, chilenos y de otras nacionalidades. La estrategia principal fue "seguir" a los informantes en sus individualidades religiosas, es decir, a través de la manifestación de prácticas, resaltando una serie de elaboraciones rituales que conducían al culto de los orichas. La mayoría de informantes cubanos coincidió en despuntar la producción literaria "afrocubana" como parte de los antecedentes culturales expresados en las tradiciones religiosas, principalmente de la Santería. De acuerdo a esto, se interesa en la discusión sobre la literatura afro-negrista con relación a la manifestación de las expresiones religiosas de ancestro africano como una matriz que ha construido identidades culturales en Cuba.
El principal cuestionamiento que hace este trabajo es el notar como la producción literaria coincide de alguna manera con el enfoque etnográfico en su manifestación de descripción densa propuesto por Clifford Geertz (2001). Los hallazgos expresados en las descripciones de Geertz sobre la pelea de gallos en una aldea de Bali, mantenían una especie de narración literaria sobre las tradiciones simbólicas locales. El autor mostró una estrategia hermenéutica en los textos, basándose en la interpretación poética de la descripción densa de la cultura como simbologías del espacio que manifestaban los objetos como entidades con significado. Ahora bien, la interpretación de la cultura desde alegorías demarcadas en los textos de Alejo Carpentier (1933 y 1949) plantea las tradiciones culturales de ancestro africano en Cuba como dicotomías políticas de reivindicación identitaria. De esta manera, no se encuentran tan alejadas de las narraciones de Geertz sobre las comunidades en Bali, pues las alegorías que prevalecen en ambos textos muestran una serie de códigos intrínsecos que expresan la tradición como extensión imaginaria de la memoria en la interpretación de significados que emergen de espacios locales, instalándose en lugares particulares de la historia. La expresión narrativa mantiene vínculos con los hechos sociales por imaginarios que estos parezcan, pues un Yoruba africano en Cuba va a seguir siendo parte de la diáspora africana en las cosas de América, así sea narrado por un literato o etnógrafo. La diferencia aquí es la manera en la que aparecen las narrativas, mientras el literato mantendrá un acercamiento con la realidad desde el momento que instala las memorias imaginarias en uno o varios escenarios, el etnógrafo tratará de mantenerse alejado de las imaginerías discursivas plasmadas en el texto a modo de descripción o narrativa. Ambas formas de narrar la realidad social, son para este autor, válidas para describir las simultaneidades culturales que aparecen en el texto como escenario de hechos reales, concretos y palpables.

\section{APROXIMACIÓN HISTÓRICA DE LA COLONIA EN CUBA}

El territorio cubano fue poblado - hasta un poco después del establecimiento de 
la Colonia- básicamente por tres grupos indígenas: Taínos, Siboneyes y Guanajatabeyes, de los cuales existen diversas hipótesis en cuanto a sus orígenes. Algunos historiadores (Arrom y García, 1988; Ortiz, 1922) asocian a estos grupos con diásporas originarias de La Florida, sur de México o de los Arauacos de la costa noroccidental de Venezuela (costa del Orinoco) en América del Sur. A la llegada de los españoles, los grupos indígenas locales mantuvieron diversos conflictos bélicos destacando a Yatahuey, líder indígena que enfrentó el régimen español siendo derrotado con sus seguidores. Fue Diego Velázquez en compañía de Hernán Cortés, Juan de Grijalva, Pedro de Alvarado y muchos otros quienes arribaron a suelo cubano en 1510, con el interés de explotar el territorio isleño sometiendo a los indígenas a largas jornadas de trabajo en los campos de cultivo, las minas, el trabajo doméstico en las haciendas y otros menesteres laborales - fueron "protagónicos de los antecedentes de la conquista, el que tuvo relación con el conquistador, el que cultivó la tierra, el de los cemíes, el casabe, areíto y tabaco" (Hernández, 2003:194).

La Colonia en Cuba se inicia con la fundación de Nuestra Señora de la Asunción de Baracoa en 1512, los españoles emprendieron el establecimiento de siete villas de acuerdo al territorio conquistado e interés estratégico, se fundó San Cristóbal de La Habana en 1514 para utilizar la costa norte, llamándola bahía de Carenas, además la de Cienfuegos llamándola Jagua en la costa sur. Otras de las villas fundadas fueron Bayamo en 1513, Sancti Spíritus y Trinidad en 1514, y Santiago en 1515, designando esta última como sede de gobierno. Las villas se estratificaron de manera clásica española: la iglesia en el centro, seguido de la plaza de armas, el ayuntamiento, el cuartel y las calles estrechas que conducían a las casas particulares. La Colonia se caracteriza por dos periodos relevantes, el primero por la condición de esclavitud de indígenas a través del sometimiento a largas jornadas laborales y el interés de evangelizarlos a modo de las doctrinas judeocristianas, el segundo, a partir de la llegada de esclavos de diversas partes de África, sobretodo de las regiones subsaharianas de las cuales pertenecían la mayoría de los reinos integrados a Yorubaland.

Las rutas transatlánticas de comercio de esclavos que dieron inicio a mediados del siglo XVI como parte de la expansión económica de Europa sobre las Américas, originó una serie de complejidades culturales de ancestro africano. Sin embargo, habría que mencionar que las estrategias geográficas (anclaje de los principales centros de enclave de esclavos) significaron una plataforma en la cual se sostienen las tradiciones de origen africano en el continente. Habría que dejar en claro que los principales tratantes de esclavos africanos fueron holandeses, franceses y portugueses, los españoles por su parte adquirían a estos durante el llamado tráfico de esclavos o trata negrera. Tanto México como Perú fueron los dos países que lograron compartir históricamente el Virreinato y la Colonia, de tal manera que el tráfico esclavo circuló de acuerdo a estos dos fuertes durante los siglos XVII-XIX, aproximadamente. Otros lugares como Panamá, Colombia y Argentina, sirvieron como espacios en los cuales se albergaban los esclavos africanos antes de ser repartidos al resto del continente. Básicamente, el Caribe fue escenario de manipulación esclava a través del cultivo de la caña de azúcar, café y tabaco, lugares como la española o Isla de Santo Domingo lo que hoy comprenden los territorios de República Dominicana y Haití, además de las Antillas: Cuba, Jamaica y Puerto Rico; las Antillas menores: Trinidad, Bermudas y Santa Lucía, además de los puertos de Cartagena en Colombia, Veracruz en México y Buenos Aires en Argentina (Chaunu, 1977; Gaslinga, 1985; Hoffman, 2006; Naveda, 1987 y Millette, 1985).

Con la presencia de los esclavos africanos surgieron múltiples manifestaciones culturales, la mayoría de estas se desarrollaron en los "barracones", lugares en los cuales convivían los esclavos después de laborar en los campos de cultivo y otros oficios. En lo que concierne a Cuba, diversas representaciones formaron parte de la identidad insular, como el Palo Monte que procedía del antiguo reino Kikongo del Congo, la sociedad secreta Abakuá del Calabar norte de Nigeria y la Santería de ancestro yoruba en la región Subsahariana que comprendía los 
territorios de Nigeria y el antiguo Dahomey (Barnet, 1997; Matory, 2001 y Menéndez, 2008). Para el caso de Brasil, el candomblé se convirtió en la tradición arraigada en la parte litoral del país, sobre todo en la región de Bahía (Carneiro, 1986; Capone, 2004; Rodríguez, 1900; Verger, 1968 y 1981), además de otras formas de practicar las tradiciones de ancestro africano como la umbanda, quimbanda $y$ batuque de origen yoruba (Ferreira, 2011; Frigerio, 1993; Giobellina y González, 1984). En Haití, el vudú de origen ashanti-yoruba se convirtió en la tradición anclada en el país (Deive, 1975; Metraux, 1953; McAllister, 2002 y Peltron, 1975). Otras tradiciones de origen africano se han considerado minorías de acuerdo a la difusión de sus prácticas e incluso el conocimiento que se tiene de las mismas, tal es el caso de gagá en República Dominicana, el Shangó cult y el rada en Trinidad y Granada, el kpelle de Santa Lucía, el kumina o pukumina y el myai de Jamaica (Barnett, 1999; Rosenberg, 1979; Simpson, 1962, 1965 y 1980).

Los países de concentración africana fueron ordenados de acuerdo a las necesidades propias, por ejemplo, en Cuba la plantación significó el eje económico de la isla, por tanto, la necesidad era traer africanos que lograran soportar físicamente las jornadas laborales. Así también en Brasil y otros lugares de las Antillas, la plantación fue el eje económico de la Colonia Portuguesa. Para el caso de Estados Unidos, el trabajo forzoso en las minas sería remplazado por los africanos, los cuales tendrían que mantenerse erguidos durante largas jornadas laborales. Después de caracterizar a los esclavos de acuerdo a la nación de procedencia, grupo y comportamiento social, biológico y cultural "les colonies américaines considérées, est alors l'origine ethnique du groupe dominant: Ashanti et Fanti, appelés aussi Akan, pour les colonie sanglaises; Dahomey (Eweou Fon) pour les franqaises; Nago (Yoruba) pour les espagnoles et les portugaises" (Herskovits, 1990:50, citado en Capone, 2000:64). Para el caso brasileño, los quince quilombos situados sobre todo en Río de Janeiro, se consideraron como enclaves de esclavos, en los cuales sobresalían los bantúes, contrarios a los quilombos de Bahía de pertenencia yoruba. Estas características repercutían en los comportamientos sociales, pues mientras que en Bahía, el control por parte de la Corona era flexible, en Río mantenían ciertas medidas de seguridad por la fuga de esclavos y otras problemáticas entre los cabildos.

La esclavitud en las Américas, sobre todo en el Caribe hispanohablante, podría situarse como un fenómeno que antecede a Europa a partir de la legalización del tráfico y el respaldo en las Leyes de Indias, reconociendo al "negro" su condición humana a través de su integración a la clase productiva $y$ sujeto a diversas leyes $y$ normas judeocristianas impuestas por la Corona de España. La idea del "negro sin alma" fue un factor relevante para ser considerados en las diversas actividades laborales como:la siembra de caña de azúcar, tabaco, café, en haciendas y otros oficios. Esta idea en torno al imaginario afroamericano inicia con la relación de esclavo/ amo durante el modelo colonial en el cual impusieron dos grandes sub-modelos evangelizadores: el católico practicado por los españoles/ portugueses y el protestante a través de los holandeses, ingleses y franceses. La trata negrera entonces fue solamente una forma de denominarse, ya que se inició a través de un intercambio complejo que vinculó a Europa, África y América, des-africanizando al "negro"a partir de la negación de su naturaleza para convertirlo en pieza de cambio, venta y producción. Así, "el africano de nación, al ser trasplantado en América, ya quedaba casi desnacionalizado y se convertía en negro, solo en negro, por su cultura en bozal $y$ por su vida en esclavo" (Ortiz, 1940:21).

Los africanos que pisaron costas cubanas entre los años 1500-1800, tenían diversas procedencias geográficas, la mayoría pertenecía a la parte occidental de África, sobre todo por la franja colonizada por ingleses $y$ franceses. La captura de estos se desarrolló en puntos estratégicos del continente, difícilmente podrían verse esclavos pertenecientes al África meridional. Los puntos de enclave y recepción de esclavos fueron las islas de Cabo Verde, el puerto de Badagri y Santo Tomé, lugares de cómoda acogida marítima para los tratantes al permanecer en buques encallados en el Atlántico hasta completar los barcos y transportarlos 
a las Américas (Calleja, 1989; Franco, 1975 y García, 1971). Estos viajes originaron una serie de conflictos internos, pues "miles de esclavos lucumíes o yorubas y bantúes o congos fueron llevados en buques de la trata, desde el siglo XVI hasta el XIX hacía las Antillas, Panamá y Sur América, en donde venían apretujados, de pie, agachados o acostados de lado" (Almengor, 2001:4). En Cuba, los yoruba se agruparon en "Lucumí-Eguadó, Lucumí-Yesa, LucumíEgba, Lucumí-Fon" (Saldívar, 2011:65). Por su parte, los bantú pertenecían a las "...etnias Vili (Loango, Fiote), Solongo, Sundi, Yombe (Mayombe), Bwende (Bembe), Lari, Mpangu, Zombo, Mbata..." (Ibíd., 2011:69). Otros grupos de esclavos arribaron "... entre 1643 y $1720 \ldots$ Después de 1820 se intensificó, en el litoral, la presencia de negreros procedentes de las islas del Indico... es precisamente en este periodo de 1840 a 1859 que se incrementa la salida de esclavos de Mozambique para Cuba y el Caribe" (Feraudy, 2007: 18).

La producción azucarera significó para la Corona un punto de partida económico, por la cual era necesaria la mano de obra esclava, revocando los derechos a la abolición constantemente (Moreno, 1978 y 1995). Entre 1811 y 1812 , se gestó uno de los movimientos abolicionistas más reconocidos en la isla, el llamado "Movimiento Aponte", el cual fue liderado por José Antonio Aponte a través del descontento por el exagerado tráfico de esclavos africanos. Cabe recordar que justamente este movimiento estaba relacionado con la Revolución Haitiana y la parte española de Santo Domingo, quienes luchaban por los derechos, la abolición $y$ la libertad de los esclavos. Para los esclavos, el barracón (quilombo en Brasil) fungió como un centro de enclave (vivienda), en el cual convivían con otros grupos, intercambiaron lenguajes, formas de cocinar, cultivar y creencias ancestrales. La noción de cimarrón, por ejemplo, etiquetaba al esclavo que escapaba del barracón, por ende, se convertía en fugitivo y además, no podría ser cubierto por otro miembro de su grupo ya que el castigo por encubrimiento era la horca (Barnet, 1997; Ortiz, 1922 y 1940). Si bien es cierto, la unificación de grupos se origina en los viajes transatlánticos y se re-afirma en los barracones, en los cuales las ceremonias mítico-religiosas tomaban forma a partir de las interacciones entre los mismos. De esta manera, la unificación de tradiciones se origina como parte de la circulación simbólica de significados ausentes en los nuevos espacios.

El trabajo en las plantaciones regularmente era para los hombres, mientras que las mujeres se encargaban de atender a los "amos" en las haciendas, cuidando los niños y preparando los alimentos. Los hijos de esclavos fungían como acompañantes de los hijos del amo, eran incluso los "juguetes" con los que crecían hasta los siete años que el esclavo iniciaba con tareas en las plantaciones. Si era mujer ayudaba a la madre en la cocina y otros quehaceres de la hacienda, si era varón seguía a su padre en la plantación para que este lo enseñara a utilizar las herramientas del campo. Por la tarde, tanto mujeres como varones iban a la escuela, la cual fungía como institución que pretendía introducir una nueva lengua. El proyecto evangelizador originó en los diversos grupos la unificación simbólica de índole religioso; es decir, la producción de esquemas imaginarios en torno a las deidades yoruba, bantú y otras etnias, junto a las judeocristianas, lo que Fernando Ortiz (1946) denominó "transculturación”. Esta amalgama de significados se estructuró a partir de diversos procesos, por un lado, la unificación de reconocimiento identitario (África como nación), por otro, la vinculación de las deidades (orichas, loas, nzambis) a través de cabildos que representaban a cada uno de los grupos.

A principios del siglo XIX, la trata negrera empezó a desaparecer, países como Francia e Inglaterra fueron algunos de los lugares que apoyaron la abolición prohibiendo el tráfico ilegal de esclavos. Martínez Montiel afirma que desde "el siglo XVII el derecho de poseer esclavos empezó a ponerse en tela de juicio... en Massachusetts se prohibió la esclavitud... En Rhode Island, se aprobó una ley en 1652 que prohibía la esclavitud por más de diez años" (2005:190). Muchos países siguieron las reglas antiesclavistas, originando a diversos movimientos que beneficiaron a Cuba y Brasil, sobre todo por encontrarse ligados al tráfico ilegal por parte de los norteamericanos. Las tradiciones religiosas 
de ancestro africano se mantuvieron a partir de la criollización como una estrategia no imaginada sino relevada por parte de los esclavos. La condición de esclavo o liberto no ocasionó una desintegración de la tradición, al contrario, mantuvo arraigadas las costumbres entre practicantes de diversas tradiciones religiosas. Por ejemplo, la Santería fue considerada casi durante el tiempo de la esclavitud en Cuba como "cosa de negros, brujería, fetichismo, prácticas orgiásticas, oscurantismo; a los santeros como brujos, gente de mal vivir, lumpen, enfermos mentales, también sus objetos rituales han sido tratados como fetiches y cacharros" (Menéndez, 1995-1996: 56).

\section{TRADICIONES RELIGIOSAS DE ANCESTRO AFRICANO EN CUBA}

En lo que refiere a las tradiciones de matriz africana arraigadas en Cuba, se describen dos grandes ramas religiosas, la Santería-Ifá y el Palo Monte, además de la regla secreta Abakuá y el espiritismo de ascendencia francesa que también se estableció en el país. La cosmovisión mítico-religiosa presente en la Santería criolla cubana obedece a tres entidades rectoras: Olórun, Olofi y Olodumare, y emisarios llamados orishas u orichas, quienes interactúan entre el mundo cósmico (dioses) y el plano terrenal (personas). Existen tres formas de comunicación oracular: biagué(cuatro pedazos de coco), diloggún(16 caracoles de mar) y ékuele $\mathrm{u}$ ókpele(cadena de adivinación acompañado de un tablero en forma circular exclusivo de los babalawos). Estos fungen como vía de comunicación entre los dioses y los humanos a través de los odún, metáforas que aluden al pasado, presente y futuro. Las jerarquías religiosas se inician a partir de procesos cultuales, ceremonias que hacen una referencia al pasado ancestral (de Souza, 1998 y 2003; Fernández, 1997 y Saldívar, 2011). La estructura de las deidades se compone de una serie de entidades conocidas como orichas, entre estos destacan: Obatalá, Yemayá, Changó, Oggún, Ochosi, Ochún, Oyá, Elegguá, Echú, Osún, Babalú Ayé, entre otros.

El Palo Monte es una práctica religiosa de origen bantú, en Cuba se ha dividido en tres líneas de acuerdo a la procedencia ancestral:mayombe, kimbisa y brillumba. El mayombe, por ejemplo, tiene un solo tipo de fundamento llamado nganga "Nsasi Siete Rayos", el cual se construye a partir de nfumbe (materia de muertos) que se deposita en un caldero con firmas ancestrales, existen al menos doce ramas: Saca Empeño Batalla, Batalla Saca Empeño, Mante Ontunga, EnsalaMayombeNgando Batalla Congo, EnsalaMayombeNgandoSese. Esta práctica aparece como una de las menos sincretizadas con el santoral judeocristiano (Castro, 2009 y 2011; James, 2006). La regla kimbisa se ha vinculado con el espiritismo llamándose regla de la orden kimbisa del Santo Cristo del Buen Viaje, fundada por Andrés Facundo Cristo de los Dolores Petit. La regla brillumba reconocen a las deidades como nfumbes y mpungos, entre estos aparecen: Siete Rayos, Zarabanda, Mamá Chola, Madre Agua, Tiembla Tierra, Lucero Mundo, Asowano. Se les rinde pleitesía a partir de ceremonias diversas, de acuerdo al munanso (casa religiosa) a la que pertenece. Existen por lo menos siete templos reconocidos en Cuba, entre estos se encuentran: Vititi Kongo, Monte Garavato, Quijenco, Zarabanda Mala Fama, Pati Congo Clava Clava, Brillumba Congo, Vence Guerra Viramundo y Vence Guerra Acaba Mundo.

Los Abakuá son considerados como una sociedad secreta, también conocida como los ñáñigos, su origen se aproxima a la región del Calabar, norte de Nigeria, por ello que en Cuba se les llamó carabalíes a los procedentes de dichas tierras, entre estos llegaron los efik, efut, orú, orón, enyón, ibibio o ekoi, entre otros. El mito de origen alude a Sikan, la hija de Iyamba, rey de los efó, quien fue a buscar agua al río y se encontró con Tanse, el pez sagrado entre los ekoi. Se desconocen oráculos utilizados por los Abakuá, solo se sabe del ékue, tambor secreto, incluso a estos se les conoce como sociedades del secreto del ékue, del tambor con voz ronca, según se cree es la voz del Dios supremo Abasí, tocado por los ekobio u hermanos iniciados. Las primeras potencias fundadas en Cuba se hicieron entre 1830 y 1835 , en los puertos de Matanzas y La Habana, los cuales se crearon en dependencia de las agrupaciones de origen, asimismo, se sabe que para 1882 llegaron a 
construirse más de 80 potencias en toda la isla y en 1855, se formó la primera hermandad Abakuá de blancos, representados todos por el "diablito Abakuá" (Castellanos y Castellanos, 1992; Miller, 2000 y Valdés, 1966).

En Cuba, una de las vertientes más populares ha sido el espiritismo, ideología de carácter religioso que aparece en el país aproximadamente en la segunda mitad del siglo XIx. Algunos especialistas en la temática señalan que la inclusión de la práctica en la isla se originó por los españoles después de haberse extendido en Europa y algunas regiones de América (Arguelles y Hodge, 1991; Castañeda y Hodge, 1998; Espinosa, 1996). Dicha corriente se originó en Francia por su representante Hippolyte Rivail conocido como Allan Kardec, quien propuso algunas pautas en torno a la cosmovisión espírita. La estructura del espiritismo se divide en tres aspectos básicos: 1) espiritismo de mesa, 2) espiritismo cruzado y 3) espiritismo de cordón. Existe un elemento importante dentro del espiritismo, la llamada "bóveda espiritual", consiste, de preferencia en una mesa que contiene seis vasos y una copa de cristal con agua, un crucifijo y flores. Se recomienda que las posiciones en los vasos deberán ir de la siguiente forma: a) reposo, dos filas verticales de tres vasos cada una $y$ en medio la copa, b) defensa, dos filas horizontales de tres vasos cada una y copa en medio y c) ataque, dos filas verticales con tres vasos cada una incluyendo la copa en medio.

\section{MATRIZ AFRICANA EN EL IMAGINARIO DE LA LITERATURA CUBANA}

En lo que refiere a la particularización de la producción literaria cubana, habría que hacer notar la influencia del movimiento artístico de reivindicación de la cultura negra surgido en Europa en 1920 de la mano de intelectuales como Aimé Cesaire, Leopold Cedar Senghor, entre otros. La negritude como movimiento cultural se asentó en París, lugar en el cual se originó como parte de un movimiento artístico cultural trascendiendo en las Antillas como poética literaria con firmes objetivos de replantear la idea de la cultura negra para no ser vista más solo como exotismo, sino como una textura cultural renaciente entre tres continentes. Estas ideas contestatarias de los valores culturales africanos vincularon a Europa y América a partir de los movimientos políticos reivindicativos en la consideración del "negro"y sus productos culturales como integrantes de las identidades locales de países de pertenencia afro. El fenómeno de la negritude en sus orígenes, se encuentra ligado a los estudiantes de color en París, aquellos como Senghor, Cesaire, Damas y otros, quienes a partir de 1932, publicaban una serie de revistas como L' Etudiantnoir, entre otras de carácter demostrativos. El proceso de mulatez poética o poesía mulata como lo llama Manuel Ferreira pertenece a un movimiento de resistencia o "cimarronajecultural" como reconocería René Depestre (1978 y 1981). El renacimiento africano en París significó para otros estudiantes afros, un espacio para convivir con sus lugares de origen, además de unirse como parte del movimiento cultural en el cual no solo era exclusivo para artistas, sino también para intelectuales como por ejemplo Jahn Jahnheinz y otros antropólogos e historiadores.

El término negritude fue acuñado por Cesaire en Cahier de retour au pays natal (1939), retomado por Senghor en Présence africaine (1959) y Jahnheinz en Muntu, an outline of neo-african literatura (1961). Los conceptos de negritude, negrismo y creolización, podrían situarse a partir del siglo xx como una forma de identificar las amalgamas socioculturales en América, sobre todo en el Caribe y las Antillas hispano-luso-francófonas. Estas identidades afrodescendientes se han hecho notar en sus variantes lingüísticas como una forma de identificar ciertos códigos culturales vinculados a los espacios geográficos y las memorias históricas que han construido las nociones de Caríbes-Antillas. En Cuba, por ejemplo, aunque ya existían algunas publicaciones antes de 1939, la idea marxista en la poética afrocubana pretendía la desmitificación del negro como producto exótico de la superioridad racial y la esclavitud, mantenían la mirada en la libertad de expresión y revaloración de las identidades como parte de una extensa amalgama cultural de los pueblos africanos en América, sobre todo a finales del siglo xIx y principios del Xx. De esta 
manera, Aimé Césaire, creador del concepto negritude y del movimiento negrísta, pretendía una búsqueda identitaria que se reivindicaba a partir del arte literario de la época. Logró vincular artistas de América y África, además que impulsó en Latinoamérica la iniciativa sobre el arte literario negrista entre países con raíces africanas del continente. Por otro lado, la negritude además de considerarse un movimiento cultural, también incursionó en una moda artística literaria que pasó a las Antillas franco-hispanas convertida en poética, proyecto cultural identitario.

La producción literaria del Caribe ha sido un conductor en la construcción de identidades, representando el imaginario caribeño a través de personajes con atributos especiales, héroes $y$ anti-héroes dinámicos. Apareciendo no solo el aspecto ontológico colectivo, sino también el entorno material que se envuelve como parte del mismo "paquete" que transmite códigos culturales. En este sentido, se menciona que la noción de esclavitud en el Caribe se encuentra estrechamente vinculada con las plantaciones, como el "lugar" en el cual sucedieron las "confrontaciones" ideológicas. De esta manera, es relevante hacer referencia a Benítez Rojo (1998 y 2007) quien manifiesta cómo el movimiento afro-cubano, antillano o negrísta, tuvo un impacto en la poética caribeña a través de la producción de otros literatos afrodescendientes, sobre todo aquellos lugares que compartían los sistemas de plantación y existían numerosos grupos de esclavos africanos. El éxito de la literatura caribeña, principalmente de los poemas de Nicolás Guillén, se deben al planteamiento de resistencia frente al desarraigo y la construcción de identidades mimetizadas. Así, las tradiciones religiosas en el Caribe se convirtieron en una especie de "enemigo" silencioso del sistema colonial a través del sincretismo religioso. Benítez Rojo en su contrapunteo de "La isla que se repite", pone en escena no solo la parte épica del Caribe, sino justamente las aproximaciones a los orígenes de lo caribeño a través de las valoraciones estéticas, políticas y socio-culturales que confirman las identidades en las cuales se encuentran inmersos códigos que aluden a la religión de ancestro africano.

Esta idea de la huida, que utiliza Benítez Rojo como metáfora para referirse a la "ausencia”, la melancolía y el extrañamiento del pasado ancestral, es también el "impulso" al retorno conocido, los orígenes, África. En el caso cubano y haitiano, se observa cómo lo religioso también se encuentra vinculado a la producción cultural; han sido las nociones de orichas-loas quienes mantuvieron el control del imaginario colectivo a partir del arquetipo de "héroes salvadores de la tierra y la humanidad". Estas consideraciones pueden ser enmarcadas a partir de la producción literaria, las artes plásticas, la música, entre otras áreas en las cuales no solo se retoma el caso afro-descendiente como pasado histórico colectivo, sino también se hace vivo a partir de "personajes" que se recuerdan a través de la oralidad, enalteciendo el pasado en el presente caribeño. Esta diversidad en el Caribe, pudo notarse fuera de sus territorios imaginados a partir de la producción literaria, revistas, círculos de interés y acontecimientos científicos. El caso de la novela antillana, por ejemplo, es relevante a partir de las caracterizaciones diversas que se reflejaban en zonas de agrupamientos de esclavos, en los que se resaltan las manifestaciones religiosas, como el caso de "Chambacú, corral de negros" (1963), "En Chimá nace un santo" (1964), "Changó el gran putas" (1965), obras de Zapata Olivella. Asimismo, se encuentran "Ecue Yamba O" (1933) y "El reino de este mundo" (1949) de Carpentier; entre otras. Estas obras hacen notar la africanidad a partir de las diferencias culturales entre los pueblos caribeños.

La producción literaria en Cuba ha sido un punto de partida con la colonización española y los "cronistas" que escribían las diferencias culturales entre los tainos y siboneyes locales, después lo hicieron con los africanos, describiendo sus costumbres, tradiciones $y$ formas diversas de comportamiento colectivo. En este sentido, podría citarse una aproximación con la obra de Bartolomé de las Casas titulada "Historia de las Indias", en la cual se llevaba un arduo registro de acontecimientos culturales, se le consideró como un punto de partida por la 
concentración de "datos" significativos en torno a la isla. Otras obras tomaron como base los clérigos propios de la Colonia en sus propuestas analíticas literarias.

A partir de 1902, después de la independencia política de Cuba sobre España y la inclusión ideológica del "criollo" como habitante de la isla, es que se inicia por así decirlo una base literaria más inclinada a la retórica identitaria, concibiéndose como una nueva literatura en la cual se aludía a las tradiciones religiosas africanas como "epicentro" clasificatorio de los grupos de esclavos. El término "criollo" en la literatura cubana es empleado por el sacerdote José de Acosta para denominar al "nacido de españoles en las Indias", a quienes no consideraban españoles pero tampoco indígenas, una forma de entender al nuevo miembro de las Américas. Silvestre de Balboa hace referencia al criollo en su poema "Espejo de paciencia", a partir del acontecimiento bélico entre un "negro" y un pirata, el primero por salvar a un sacerdote y ser considerado después "salvador criollo, negro honrado". En ese tiempo, la literatura cubana se consideró como constructora de nacionalidad a partir de las políticas identitarias y revolucionarias en la isla, además, por el vínculo socio religioso que acontecía en Cuba, sobre todo en los principales "palenques" de La Habana, Matanzas y Oriente.

La época colonial dotó de paisajes alternos a los literatos cubanos, entre estos, Felipe Pichardo Moya quien aludió a la poesía negrísta desde una visión modernista en la cual resaltaban poemas como "La ciudad de los espejos", "Zafra", "Cantos de isla", entre otros. En este "equipo" de ensayistas y literatos cubanos, se cita a Fernando Ortiz como un intelectual, que si bien no se dedicó a los estudios literarios, sentó las bases conceptuales en torno a los problemas raciales que imperaban en la isla desde principios de la Colonia, problemáticas ligadas al "negro" y sus símbolos religiosos. Citar las obras de Ortiz sería interminablemente conocido, más bien sería relevante mencionar cómo los estudios de Ortiz influyeron como soporte en la producción literaria de Cuba, a partir de la construcción de conceptos como "transculturación" y su metáfora conocida como "el ajiaco cubano", en el cual pretende desentrañar las amalgamas culturales producto de los diversos grupos de esclavos recolocados en suelo cubano.

La poesía negrísta como se le llama en la actualidad, es representada por Nicolás Guillén, como el más prominente en el territorio cubano, la integración de sus versos ligados a caracteres identitarios fueron pilares en la construcción de la cubanía, la cubanidad y la caribeñidad. Se interesó por resaltar las tradiciones culturales de los esclavos africanos en la isla a través de una serie de aspectos que van desde las cuestiones raciales hasta las nociones culturales de los mismos. La producción de Guillén es relevante en medida de los señalamientos sobre los procesos de esclavitud y después de esta; sin embargo, lo que interesa resaltar en este trabajo es justamente lo que refiere a las tradiciones religiosas de ancestro africano. Aparecen Motivos de son (1930), aludiendo al folclore musical de los "poemas mulatos"; además de Songoro cosongo (1931) como uno de sus poemas más populares y consagrados, en el cual hacía alusión a las tradiciones religiosas africanas. La poesía negrista mantenía una serie de alegorías que hacían referencia a las tradiciones religiosas de matriz africana. Se señalan algunos ejemplos en tres extractos poéticos de Guillén: Canto negro, Sensemayá y Songoro cosongo.

Ej. 1 Yambambó, yambambé! Repica el congo solongo, repica el negro bien negro; congo solongo del songo, baila yambó sobre un pie. Mamatomba, serembe cuserembá. El negro canta y se ajuma, el negro se ajuma y canta, el negro canta y se va. Acuememe serembóaé; yambó, aé. Tamba, tamba, tamba, tamba, tamba del negro que tumba; tumba del negro, caramba, caramba, que el negro tumba: ¡yamba, yambó, yambambé!(1947:302).

Ej.2 ¡Mayombe-bombe-mayombe! ¡Mayombebombe-mayombe! ¡Mayombe-bombemayombe! La culebra tiene los ojos de vidrio; la culebra viene y se enreda en un palo; con sus ojos de vidrio, en un palo; 
con sus ojos de vidrio. La culebra camina sin patas, la culebra se esconde en la yerba, caminando se esconde en la yerba, caminando sin patas. ¡Mayombe-bombemayombe! ¡Mayombe-bombe-mayombe! ¡Mayombe-bombe-mayombe! Tú le das con el hacha $y$ se muere: idale ya! No le des con el pie, que te muerde, no le des con el pie, que se va. Sensemayá, la culebra, sensemayá. Sensemayá, con sus ojos, sensemayá. Sensemayá, con su lengua, sensemayá. Sensemayá, con su boca, sensemayá (1934:148-149).

Ej. 3 Yoruba soy, lloro en Yoruba lucumí como soy un Yoruba de Cuba, quiero que hasta Cuba suba mi llanto Yoruba, que suba el alegre llano Yoruba que sale de mí. Yoruba soy cantando voy llorando estoy $y$ cuando no soy Yoruba, soy Congo, Mandinga y Carabalí. Estamos juntos desde muy lejos, jóvenes, viejos,negros $y$ blancos, todo mezclado; uno mandando $y$ otro mandado, todo mezclado; San Berenito $y$ otro mandado todo mezclado; negros y blancos desde muy lejos todo mezclado (1947: 231).

Otro género que evolucionó en Cuba fue la novela, en el cual Alejo Carpentier destacó de manera prominente a través del surrealismo francés del cual estaba influenciado notablemente. El género literario desarrollado por Carpentier fue conocido como imaginativo a partir de su dote de "real maravilloso", en el cual pretende mitificar los arquetipos de sus personajes. Ecué-Yamba-O fue publicada en 1933, narra la historia de Menegildo Cué, afro-descendiente que se encuentra rodeado de símbolos religiosos afrocubanos, con los que se identifica y recuerda el pasado ancestral. Esta folclorización que hace Carpentier es relevante para determinar lenguajes de índole religioso que se encontraban aún "ocultos" dentro de algunos grupos de practicantes religiosos, sobre todo afrocubanos. Así también en el Reino de este mundo, escrita en 1949, narra la historia del esclavo Mackandal y tío Noel en Haití, quienes se valen de las metamorfosis producidas por las divinidades vudú para mantenerse entre la conspiración arrebatadora de la colonia francesa en el reciente país de los loas. Se señala un fragmento de la novela titulado El pacto mayor.

Fai Ogún, Fai Ogún, Fai Ogún, oh!Damballah m'ap tiré canon! Fai Ogún, Fai Ogún, Fai Ogún, oh! Damballah m'ap tiré canon!...Ogún de los hierros, Ogún el guerrero, Ogún de las fraguas, Ogún mariscal, Ogún de las lanzas, Ogún-Changó, OgúnKankanikán, Ogún-Batala, OgúnPanamá, Ogún-Bakulé, eran invocados ahora por la sacerdotisa del Radá, en medio de la grita de sombras. (1949: 41)

La apariencia religiosa expresada en las novelas de Carpentier son en medida de la ficción imaginativa o maravillosa con las que se muestran, incursiones etnográficas en las cuales se relata de manera sensata parte de la tradición oral de ancestro africano en el $\mathrm{Ca}$ ribe, siendo Cuba y Haití los países en los que centra sus narraciones. Estas ideas en torno a lo pintoresco que pueden parecer los relatos literarios, son útiles en medida que ponen en escena una serie de códigos culturales que hacen reflexionar en la tradición como extensión de la memoria histórica, colectiva e individual de un espacio determinado.

La pintura cubana de la mano de Wilfredo Lam, podría situarse como parte de la producción de artistas inspirados en el movimiento de la negritud, pues han sido sus obras dedicadas a los orichas las que han mantenido el arte revolucionario cubano, sobre todo por entender este arte como una re-evolución espiritual más que física. Su obra maestra, Oggún arere, se origina después del viaje que realizó a Haití en el cual logra presenciar algunas ceremonias del vudú, imponiéndole una serie de atributos imaginativos que logra plasmar en sus trabajos posteriores sobre lo africano. Una de las cuestiones que debería tratarse en torno a la producción de Lam, es la del exilio, pues ha sido a través de las experiencias fuera de Cuba las que lograron impulsarlo a notar una serie de singularidades en torno a lo africano. La formación en Europa y el roce con artistas cosmopolitas, 
hace de Lam un pintor surrealista que pretendía desmitificar la africanidad, convirtiéndola en parte de una extensa tradición propia, es decir, cubana por adopción. Otras visiones del pintor como la que expresa en La silla o La jungla, además de representar una imaginación al estilo Jung, pretende mantener la relación con la espiritualidad africana-cubana a partir de atributos imaginarios en los que aparecen cañas, vegetación y otras miradas que representan a las deidades de ancestro africano. Así también, la influencia de intelectuales como Lydia Cabrera, quien incluso plasmó algunas de sus ideas en las imágenes pintorescas de Lam, fueron de interés en medida que lograron establecer la conexión entre África y Cuba - después de un periodo de manumisión establecido- $-y$ lo contemporáneo de la realidad política caribeña en general.

Si bien es cierto, tanto Alejo Carpentier como Wilfredo Lam, además de compartir el exilio en Europa, ambos poseen un interés por regresar a Cuba y resaltar la africanía, esta vez de la mano del movimiento político más significativo en la isla, la revolución cubana a la cual apoyaron desde sus trincheras artísticas. Este "caballo de troya real maravilloso", significó una plataforma en la construcción identitaria de Cuba, pues más allá de manifestar la africanía, resaltaron la imagen política del Caribe surrealista que pretendía la expresión de un cúmulo de sintonías culturales crecientes. Ambos mostraron la Cuba del júbilo, de la gloria y la realidad a partir del componente intrínseco africano, como sostuvo de manera aseverativa Fernando Ortiz, del ajiaco cubano como elemento de distinción cultural del Caribe hispanohablante. Las obras literarias, artísticas y poéticas tanto de Carpentier como de Lam y Guillén, representan la extensión africana a partir de metáforas que expresan parte de la realidad cubana en sus procesos de manifestación cultural, pues la brujería de la mano de los orichas, loas y zambis, parecía hablar un lenguaje de resistencia. De manera que, "en el reino de los cielos no hay grandeza que conquistar, puesto que allá todo es jerarquía establecida ...el hombre solo puede hallar su grandeza, su máxima medida en $E l$ reino de este mundo" (Carpentier, 1949:143, citado en Birkenmaier, 2003:213).

\section{CONCLUSIÓN}

Los estudios literarios han mantenido acercamientos con la Antropología a partir de la narración como enfoque descriptivo de espacios, lugares, personas o hechos sociales por imaginarios que parezcan. De esta manera, la producción literaria va más allá de una simple descripción local del texto como pretexto, esbozando la imaginación desbordada de una serie de acontecimientos que mantienen regularidades entre el lector $y$ aquellos que aparecen detrás de las letras resueltas.

La crítica literaria se ha erguido - como opinión personal- en un modelo consistente que no pretende opacar otras áreas de las ciencias sociales, sino mantenerse como una estrategia viable de entender a los otros en sus imaginarios constantes de significado. Por esta razón, surgen las interrogantes: ¿qué pretende un literato cuando amenaza con colmillos, piedras y flechas las apariencias de espacios diversos cercanas a la realidad?, ¿acaso no se aproxima a una descripción densa de la cultura como símbolo y significado dicotómicos?

La formación discursiva es una manera de entender el lenguaje a partir de la emisión de enunciados sobre situaciones o acontecimientos sucedidos, por lo cual, la realidad social mediada por los hechos no deciden su verdad o falsedad, son consideradas como tal de acuerdo a cada cuerpo discursivo en los que se inscriben. De esta manera, la producción literaria no puede considerarse solo como imaginaria por no situarse en una alegoría etnográfica singular, al contrario, debería pensarse como una estructura discursiva que pretende mantener sus propias categorías, imágenes y formas de ver el mundo en su contenido cultural.

\section{BIBLIOGRAFÍA}

LIBROS

Arguelles Alexei e Ileana Hodge. 1991. Los llamados cultos sincréticos y el espiritismo. La Habana, Cuba: Editorial Academia. 
Arrom, José y Manuel García. 1988. El murciélago y la lechuza en la cultura Taína. Santo Domingo, República Domuinicana: Fundación García Arévalo.

Barnet, Miguel. 1997. Biografía de un cimarrón. Buenos Aires, Argentina: Centro Editor de América Latina.

Barnett, Miguel. 1999. La shonda. Callaloo \& other lesbian love tales. Norwich, Inglaterra: New Victoria Publisher.

Benítez Rojo, Antonio. 1998. La isla que se repite. Barcelona, España: Editorial Casiopea.

Benítez Rojo, Antonio. 2007. "Music and Nation". En Cuba.idea of a Nation Displaced, editado por Andrea O' Reilly Herrera, 328-340. Nueva York, EEuU: State University of New York Press.

Cabrera, Lydia. 1957. Anagó vocabulario Lucumí. Miami, EEUU: Ediciones Universal.

Cabrera, Lydia. 1954. El monte. La Habana, Cuba: Editorial SI-MAR.

Cabrera, Lydia. 1980. Koekóiyawó, aprende novicia: pequeño tratado de regla Lucumí. Miami, EEuU: Ediciones Universal.

Cabrera, Lydia. 1970. Otániyebiyé: las piedras preciosas. Miami,EeUU: Ediciones Universal.

Cabrera, Lydia. 1974. Yemayá y Oshún. Madrid, España: Ediciones CR.

Calleja Leal, Guillermo. 1989. Estudio de un sistema religioso afro-cubano: el Palo Monte mayombe. Madrid, España: Universidad Complutense de Madrid.

Carneiro, Edison. 1986. Candomblés de Bahia. Rio de Janeiro, Brasil: Civilização Brasileira.

Carpentier, Alejo. 1949. El reino de este mundo. Ciudad de México, México: Edición $y$ Distribución Iberoamericana de Publicaciones.

Carpentier, Alejo. 1989. Ecué-Yamba-O. Ciudad de México, México: Alianza Editorial.

Castellanos, Jorge e Isabel Castellanos. 1992. Cultura afrocubana (Tomo3). Miami, EEUu: Universal.

Cesáire, Aimé. 1971. Cahier de retourau pays natal. París, Francia: Présence Africaine.
Chaunu, Pierre. 1977.Séville et l'Amérique aux XVI fet XVII fsiécles. Paris, Francia: Flammarion.

De souza, Adrían. 1988. Echú-Elegguá. Equilibrio dinámico de la existencia. La Habana, Cuba: Ediciones Unión.

De souza, Adrián. 2003. El sacrificio en el culto de los Orichas. La Habana, Cuba: Ifatumó.

Deive, Carlos. 1975.Vudú y Magia en Santo Domingo. Santo Domingo, República Dominicana: Museo del Hombre Dominicano.

Feraudy, Heriberto. 2007. Macúa. La Habana, Cuba: Editorial de Ciencias Sociales.

Fernández, Tomas. 1997. Hablen paleros y santeros. La Habana, Cuba: Editorial de Ciencias Sociales.

Franco, José Luciano. 1975. La diáspora africana en el Nuevo Mundo. La Habana, Cuba: Ed. Ciencias Sociales.

García Cortez, Julio. 1971. El santo (la ocha) secretos de la religión lukumi. Miami, EEUU.

Gaslinga, Cornelio. 1985. Los holandeses en el Caribe. Cuba. La Habana, Cuba: Casa de las Américas.

Geertz, Clifford. 2001. "Juego profundo: notas sobre la riña de gallos en Bali". La interpretación de las culturas. Barcelona, España: Gedisa.

Guillén, Nicolás. 2002. Antología. Distrito Federal, España: Fondo de Cultura Económica (FCE).

Jahn, Jahnheinz. 1961. Muntu, an outline of Neo-African culture. New York,EEuU: Trans. Margaret Green-Grow Press.

James, Joel. 2006. La brujería cubana: el Palo Monte. Santiago de Cuba: Editorial Oriente.

Martínez Montiel, Luz María. 2005. Afroamérica. La tercera raíz. Madrid, España: Edición digital-Instituto histórico Tavéra.

Mcallister, E. 2002. Rara! Vodou, power and performance in Haiti and its diaspora. Berkeley, EEuU: University of California Press.

Metraux, Alfred. 1953. Medicine et vaudouen Haití. París, Francia: Gallimard. 
Millete, James. 1985. El sistema colonial inglés en Trinidad (1783-1810). La Habana, Cuba: Casa de las Américas.

Moreno Fraginals, Manuel. 1995. Cubal España, España/Cuba: Historia común. Barcelona, España: Crítica.

Moreno Fraginals, Manuel. 1978. El ingenio: complejo económico social cubano del azúcar. La Habana, Cuba: Editorial Ciencias Sociales.

Naveda, Adriana. 1987. Esclavos negros en las haciendas azucareras de Córdoba, Veracruz, 1690-1839. Xalapa, México: Universidad Veracruzana.

Nina Rodrigues, Raymundo. 1900. L' animismefétichiste des Nègres de Bahia. El Salvador: Reis \& Companhia Editora.

Ortiz, Fernando. 1940. Contrapunteo cubano del tabaco y el azúcar. La Habana, Cuba: Editorial de Ciencias Sociales.

Ortiz, Fernando. 1946. El engaño de las razas. La Habana, Cuba: Editorial de Ciencias Sociales.

Ortiz, Fernando. 1922. Historia de la arqueología indocubana. La Habana, Cuba: Siglo Xx.

Peltron, Robert. 1975. Los secretos del Vudú. París, Francia: Bruguera.

Rosemberg J. 1979. El Gagá religión y Sociedad de un culto dominicano. Santo Domingo: Universidad Autónoma de Santo Domingo (UASD).

Sédar-Sengor, Leopold. 1959. L'esprit de la civilisationou les lois de la culture negro africaine. París, Francia: Présence Africaine.

Simpson, Georges. 1980. Religious cults of the Caribbean: Trinidad, Jamaica and Haití. San Juan, Puerto Rico: Universidad de Puerto Rico.

Verger, Pierre. 1981. Orixás: deuses Yorubás na África e no novo mundo. El Salvador: Corrupio.

Verger, Pierre. 1968. Flux et reflux de la traite des négres entre le Golfede Bénin et Bahia de todos os santos. París, Francia: Mouton.

Zapata, Manuel. 2010. Changó el gran putas. Bogotá, Colombia: Ministerio de Cultura de Colombia.
Zapata, Manuel. 1963.Chambacú, corral de negros. Bogotá, Colombia: Editorial Bedout.

Zapata, Manuel. 1964. En Chimá nace un santo. Medellín, Colombia: Seix Barral.

PUBLICACIONES PERIÓDICAS

Birkenmaier, Anke. 2003. "Alejo Carpentier y Wifredo Lam: Negociaciones para un arte revolucionario". Anales de Literatura Hispanoamericana 32: 205-213.

Capone, Stefania. 2004. "A propos des notions de globalisation et de transnationalisation". Civilisations. Revueinternationale d' anthropologie et de sciences humaines 1-2: 9-21.

Capone, Stefania .2000. "Entre Yoruba et Bantou: l'influence des stéréoty pesraciaux dans les études afroaméricaines". Cahierd'études africaines 157, n. ${ }^{\circ} 40: 55-77$.

Castañeda, Yalexei e Ileana Hodge. 1998. Espiritismo Cruzado. Creencias y símbolos en la práctica ritual. (Artículo inédito). La Habana, Cuba: Departamento de Estudios Sociorreligiosos (DESR).

Castro, Luis. 2011. “'Arrear el muerto': sobre las nociones de trabajo en las religiones afrocubanas practicadas en Bogotá". Maguaré 25, n. ${ }^{\circ}$ 2: 89-119.

Castro, Luis. 2009. "Con licencia de Zarabanda': violencia y ritual en el Palo Monte en Bogotá". Scripta Ethnologica 31: 33-48.

Depestre, René. 1978. "Problemas de la identidad del hombre negro en las literaturas Antillanas". Cuadernos de Cultura Latinoamericana 14.

Depestre, René. 1981. "Una ejemplar aventura de cimarroneo". El Correo de la UNESCO 34: 16-21.

Espinosa, Eduardo. 1996. "En compañía de los espíritus". Alteridades 12, n. ${ }^{\circ}$ 6: 77-97.

Ferreira, María. 2011. "Cocinando identidades en el Caribe expandido: literaturas, comidas y música". Cuadernos de literatura 30, julio-diciembre: 88-106.

Frigerio, Alejandro. 1933. "La invasión de las sectas". Sociedad y Religión 10/11: 32-69. 
Giobellina, Fernando y Evangelina González. 1984. "Umbanda. Notas sobre un fenómeno religioso brasileño". Revista Española de Antropología Americana14. Acceso el 12 de marzo de 2014. http:// www.ucm.es/Bucm/revistas/ghi/05566533/ articulos/REAA8484110227A.PDF.

Hoffman, Odile. 2006. "Negros y afromestizos en México: viejas y nuevas lecturas de un mundo olvidado". Revista Mexicana de Sociología 1, n. ${ }^{\circ}$ 68: 103-135.

López Valdés, Rafael. 1966. "La Sociedad Secreta 'Abacuá' en un Grupo de Obreros Portuarios". Etnología y Folklore 2.

Matory, James. 2001. "El nuevo imperio Yoruba: textos, migración y el auge transatlántico de la nación Lucumí". Culturas encontradas: Cuba y los Estados Unidos. Coordinado por Rafael Hernandéz y John H. Coastworth, 167-168. EeuU. Centro de Estudios Latinoamericanos David RockefellerUniversidad de Harvard.

Menéndez, Lázara. 2008. "Kinkamaché to gbogbo Oricha. Foléowó, foléayé, foléaché". En, América Latina y el Caribe. Territorios religiosos y desafíos para el diálogo. Compilado por Aurelio Alonso, 229-256. Buenos Aires, Argentina. Consejo Latinoamericano de Ciencias Sociales (Clacso).
Menéndez, Lázara. 1995. "La Santería que yo conozco". Société Suisse des AmericanistesBulletin59-60, octubrediciembre.

Miller, Ivor. 2000. "A Secret Society Goes Public: The Relationship between Abakuá and Cuban Popular Culture." African StudiesReview 43, n. ${ }^{\circ}$ 1: 161-88.

Simpson, Georges. 1962. "The Rastafari movement in Jamaica in its millennial aspect". Millennial Dreams in Action. Editado por Sylvia Thrupp. Netherlands: The Hague, Mouton and Company.

Simpson, Georges. 1995. "The Shango Cult in Trinidad".Caribbean Monograph Series 2.

TESIS

Almengor, Dagoberto. 2001. "Santería en la ciudad de Panamá (1960-2000)”. Tesis de Maestría. Universidad de Panamá.

Saldívar, Juan. 2011. "Un silbato para Elegguá. La producción transnacional de la Santería en la ciudad de Lima". Tesis de Maestría en Antropología Social. Pontificia Universidad Católica del Perú.

Fecha de ingreso: 19/11/2014 Fecha de aprobación: 18/05/2015 
